\title{
Reflections on a participatory research project exploring bullying and school self-exclusion: power dynamics, practicalities and partnership working
}

\author{
Dr Niamh O’Brien ${ }^{\mathrm{a} *}$
}

orcid.org/0000-0002-2738-8514

\author{
Anna Dadswell ${ }^{\mathrm{b}}$ \\ orcid.org/0000-0002-1568-202X
}

${ }^{a}$ School of Education and Social Care, Anglia Ruskin University, Chelmsford, UK;

${ }^{b}$ School of Education and Social Care, Anglia Ruskin University, Chelmsford, UK;

*corresponding author: Dr Niamh O’Brien,

Senior Research Fellow, Faculty of Health, Education, Medicine and Social Care

Michael Salmon Building, Anglia Ruskin University

Bishop Hall Lane, Chelmsford CM1 1SQ

Niamh.obrien@anglia.ac.uk

+44 (0)1245 684957

Niamh O'Brien is a Senior Research Fellow in the Faculty of Health, Education, Medicine and Social Care at Anglia Ruskin University. Her expertise is in undertaking participatory approaches to research involving young people. Her doctoral work used PAR methodology to explore bullying at an independent day and boarding school alongside school students. Niamh's interests are in bullying and enabling young people to have a voice in areas which interest and/or affect them.

Anna Dadswell is a Research Fellow in the Faculty of Health, Education, Medicine and Social Care at Anglia Ruskin University. Her research interests are in the use of inclusive and creative methodologies to explore the mental health and wellbeing of marginalised groups, including women and young people. 


\title{
Reflections on a participatory research project exploring bullying and school self-exclusion: power dynamics, practicalities and partnership working
}

\begin{abstract}
Young people who self-exclude from school often cite bullying as a central reason; yet there is a paucity of research on this topic. Moreover, there is no participatory research exploring this issue alongside young people.

Using participatory research, we worked with Red Balloon Learner Centres, who provide educational/therapeutic support to young people after self-exclusion. In phase one, we worked with staff and young people to co-develop an understanding of bullying and co-design the research methods and analytical framework for the study. In phase two, young people from across the Centres participated in focus groups.

This participatory process highlighted how the intentions and realities of this approach often conflict with one another. Reflections therefore include:

Power dynamics: The research team had a wealth of knowledge from lived experiences, to practical knowledge/experiences to academic knowledge. By recognising these contributions, power was perceived as fluid, ever changing as the project developed.

Practicalities of participation: Young people had competing priorities and some chose not to participate. We were respectful of this and worked flexibly to provide participation opportunities.

Partnership working: Building rapport with Red Balloon was essential for sensitively identifying young people interested in the research and encouraging/supporting them throughout their participation.

This research adds to literature on the need for flexibility and responding appropriately to experiences when involving young people in sensitive research. It further offers a strong rationale for involving young people in future studies to develop support that better fits the needs of bullied young people to reduce incidences of self-exclusion.
\end{abstract}

Keywords: participatory research, bullying, self-exclusion, young people 


\section{Introduction}

This paper reports on the process of conducting a participatory research project with young people to understand their experiences of self-exclusion from school due to severe bullying ${ }^{1}$. We begin by introducing connections between bullying and self-exclusion, followed by a review of the literature on young people's right to participation and their involvement in research. We then discuss our research design and how we worked with young people who have lived experiences of bullying leading to self-exclusion, as well as Red Balloon, the charity who supported them to participate. Next, we reflect on three key themes that emerged as a result of the process: power dynamics; practicalities of participation and partnership working.

We conclude by asserting the importance of involving young people with lived experiences in this sensitive research because this involvement recognises their unique experiences and knowledge which goes beyond that of the current literature on bullying and self-exclusion from school.

\section{Bullying and self-exclusion from school}

School bullying is recognised as a global public health, educational and mental health concern (see for example Smith, 2014; Rigby, 2019). Bullying can be defined as intentional, aggressive acts carried out repeatedly and over time by a group or individual against a victim who cannot easily defend themselves (Vaillancourt, McDougall, Hymel, Krygsman et al., 2008). Studies exploring this phenomenon have taken many guises from largescale cohort studies (see Benbenishty, Astor, Roziner \& Wrabel, 2016) to smaller qualitative studies (see Thomson \& Gunter, 2008). Research on school bullying is plentiful in the literature (see for example Salmivalli, 2010; Smith, 2014), with fewer studies conducted from the viewpoint of young people themselves (O’Brien, 2019). Bullying studies using a participatory approach facilitate knowledge co-production between adults and young people as they work together to

\footnotetext{
${ }^{1}$ The findings from the study are presented elsewhere (O’Brien \& Dadswell, 2019).
} 
understand the complexities of the contextual and relational aspects of bullying, as well as the particular challenges associated with addressing it (O’Brien, 2019).

However, studies exploring bullying with those no longer attending mainstream education are rare, meaning that young people who self-exclude are absent from this discourse. Selfexclusion refers to when a child or young person decides themselves, to stop attending school on a permanent basis (O'Brien \& Dadswell, 2019). It is different from 'being excluded' or 'truanting' from school, and is sometimes referred to as 'school refusal' (see Thambirajah, Grandison \& De-Hayes, 2008). We use the term 'self-exclusion' in line with existing discourses from practitioners working in this area as well as a recent report on bullying and self-exclusion (Centre for Social Justice, 2016; Red Balloon, 2019). Self-exclusions are not recorded in any official statistics in the UK, making this a hidden issue. Young people who have self-excluded often cite bullying as a central reason (Brown, Clery \& Ferguson, 2011). Yet studies exploring the link between bullying and self-exclusion are absent from the literature (O’Brien \& Dadswell, 2019). Billington (2018, p.349) states:

"Empowering children and young people to build rapport with adults, communicate and jointly problem-solve is likely to promote inclusion in processes, rather than reinforcing a view that decisions regarding children missing education are made by others with preconceived ideas about how best to support."

In order to understand the experiences and support needs of these young people, a participatory approach for this research project was considered appropriate.

\section{Young people's right to participation}

Kellett (2010a) argues that although adults are more knowledgeable than children with regards to many life events, children are experts in their own unique childhoods and what it is like to be a child now. This principle underpins Article 12 of the United Nations Convention on the 
Rights of the Child (UNCRC) (1989), which outlines the protection, provision and participation rights of children and young people under the age of 18 years across the world. Whilst recognising that children and young people have the right to be included in decisions made about them, the UNCRC links these rights to inclusion, empowerment and agency (Freeman, Nairn \& Sligo, 2003). Nevertheless, it is not enough to acknowledge that children and young people have the right to be heard and to actively participate. They must be provided with opportunities, that are not 'one off' or 'add on' activities, but embedded within the system to accommodate participation (Percy-Smith \& Malone, 2001; Fitzgerald, Graham, Smith \& Taylor, 2009).

The discourse surrounding children's voice therefore, is underpinned by the willingness of adults to listen (Komulainen, 2007; Kellett, 2010a) in particular to marginalised groups of children and young people. Within a school context, how pupils are encouraged to speak out and have a say is often dependent on what can be said, by whom and in what ways (Cremin, Mason \& Busher, 2011; Horgan, 2017). Further, Cremin, Mason and Busher (2011) suggest that the way in which 'pupil voice' is framed will impact on how adults respond. Indeed adults can discredit the value of children's voices when they question the competencies, age and maturity of the child and make assumptions about the credence of their statements (Komulainen, 2007; McNamee \& Seymour, 2012). James (2007) cautions that promoting children's voices is not always about permitting them to speak; it is about exploring the unique contribution to knowledge that they can make so adults can theorise and understand the social world that they occupy. Furthermore, Bradbury-Jones, Isham and Taylor (2018) highlight that 'children's voice' as a concept is problematic, as 'giving voice' assumes that children and young people do not have a voice in the first place. Indeed, children and young people can choose not to participate in adult designed projects and their silence can be just as important as exercising their voice (Bradbury-Jones, Isham \& Taylor, 2018). 


\section{Involving young people in research}

Whilst the UNCRC (1989) does not specifically refer to research, it is nevertheless important given that it stipulates young people's competence and ability to participate more generally (Wilkinson \& Wilkinson, 2018). Set against the backdrop of children's rights and the New Sociology of Childhood (James, 2007), this paradigm shift recognises the value placed on listening to and understanding what young people have to say. A participatory research design involves young people in the research process either all the way through or during parts of it and recognises that participation can be occurring even when young people are not the main decision makers (Moules \& O’Brien, 2012). Percy-Smith (2015) reiterates this point when he suggests that participation is not solely about the decisions made, but about the sense of independence and free will people experience when they participate as part of their own agenda. This rigorous research process therefore values the involvement of young people with direct experience of the issue from the outset. Nonetheless, Wilkinson and Wilkinson (2018) note that young people may desire to only participate in one or two aspects of a project and within a participatory approach this should be accommodated.

Bradbury-Jones, Isham and Taylor (2018) conducted a qualitative systematic review on the methodological, ethical and practical issues involved in conducting participatory research with vulnerable and marginalised groups of young people. They highlight that academic understanding of a research topic is largely underpinned by theoretical knowledge of the issue as well as the general interest and possible life experiences of the researcher, but that young people have experiential knowledge as experienced in real time, which offers a different viewpoint to the subject area. They further suggest confusion in terminology and definitions associated with what participatory research is and what it should be, largely related to the "rapid pace of innovation" (p.81) in the field. Referring to the work of Bishop (2014), BradburyJones, Isham and Taylor (2018) reflect that participatory research happens when children and 
young people receive research training and are involved in the research process in the same or equivalent role as adults in some or all stages of the research. The term 'co-production', they argue, is central to the philosophy of participatory research. Consequently, involving young people in participatory research, designed to co-produce new knowledge with them, challenges the traditional positioning and involvement of young people within the research process. Participatory research provides space to enable young people to exercise their views in a meaningful way and has proven particularly useful in a number of domains, such as service use in a local authority (O’Brien \& Moules, 2007) and exploring bullying at an elite school (Stoudt, 2009). In advocating for young people's active involvement in research, Kellett (2010b) suggests that benefits are not only evident in the outcomes of the research but also in the personal development of young researchers and potential changes for others. Moules and O'Brien (2016) echo this point and describe young researchers feeling a sense of achievement and being valued during the process, as well as gaining an in-depth understanding of research. This is particularly important for those deemed vulnerable and whose voices are largely absent from the literature (Brady, Templeton, Toner, Watson et al., 2018).

Despite changes in policy and legislation in ascertaining the views and wishes of young people in relation to decisions that affect them, less attention has been paid to the experiences and impact of this involvement compared to adult involvement (Bird, Culley \& Lakhanpaul, 2013). Brady et al. (2018) advocate that involvement should enable research that ultimately leads to services for young people that better reflect their needs. However, Wilkinson and Wilkinson (2018) note that it is not always possible to involve young people in setting the agenda prior to the research process and refer specifically to bid writing, which is usually conducted fully by adult researchers. Indeed, involving young people in participatory research is not without its challenges. The ideology of participatory research does not always align with the priorities of young people or the organisations that support them. Young people's lives are complex and 
multifaceted and the difficulties of hearing from them about how they experience aspects of their lives within a school or social context are further exacerbated when they are not attending school.

\section{Study design}

Our participatory approach aimed to provide young people with the opportunity to be involved in the research as co-researchers over two phases and to be as participatory as possible, although flexibility was key. We worked with Red Balloon, an English charity who provide educational and therapeutic support to young people who have self-excluded from school as a result of severe trauma usually involving bullying. Red Balloon work with young people to build self-confidence, get them back on track academically, and help them reconnect with society. With four physical Centres in Cambridge, Norwich, Northwest London and Reading, Red Balloon currently provide face-to-face support to approximately 80 young people (Red Balloon, 2015). They also have online provision known as Red Balloon of the Air (RBAir), which offers support to a further 100 young people.

Similar to the work of Brady et al. (2018), the research proposal was initiated by adults rather than developed as the result of a collaboration with young people. Fox (2013), in her participatory research with four young people in Scotland experiencing exclusion from school, discusses constraints placed on young people's involvement in research by large academic institutions. She argues that ethical guidelines, in particular, are usually unfamiliar with the theoretical underpinnings that children are viewed as social actors and therefore rarely allow topic guides to be collaboratively developed with them as the process develops. This was not the case in our study, (see ethical considerations below), and although the proposal was written by adults, the initial ideas were informed by a small-scale study that the first author had conducted with Red Balloon previously, which explored the stories of young people and their mothers about self-exclusion due to severe bullying (O'Brien, 2017). The findings 
demonstrated the value of hearing young people's individual stories expressed in their own way, which resonates with participatory research approaches of involving young people in designing the research questions from their perspectives rather than adult-led questions (Jones, 2004), and in deciding who should be involved and how.

Accordingly, the research design of the current study began by working with young people and staff at RBAir as co-researchers, who co-designed the research questions, methods and analytical framework, alongside university researchers in phase one. Phase two, then involved data collection with young people from each of the other Red Balloon Centres.

\section{Phase one: working with the research team}

During this first phase, we formed a research team comprising two young people from RBAir, two members of RBAir staff and two university researchers (the authors). Our intention was to work with a group of five or six young people as co-researchers through the two research phases but as the project developed, it became apparent that we had to be flexible in our approach (Brady et al., 2018). Given that RBAir were largely providing online support, with some young people physically attending the Centre on a weekly basis, we could only work with those who were present at the time and wanted to join the study. Bradbury-Jones, Isham and Taylor (2018) highlight that participatory research cannot be expected to be representative of a larger group, and Brady et al. (2018) report that although seventeen young people played a role in their advisory group, only two maintained regular involvement. In our study, this was somewhat ameliorated by the involvement of two RBAir staff members, who were able to draw on their wealth of experience supporting many students through unique circumstances. In this way, the research was also strengthened through the triangulation of multiple perspectives: young people with lived experiences, RBAir staff with practice knowledge and experiences, and university researchers with research expertise. Consequently, with multiple perspectives and knowledge on the issue, power relations were balanced on the team, which contributed to the 
trustworthiness and legitimacy of the data as well as empowering young people as coresearchers and co-creators of knowledge. Our research team worked together over three discursive sessions to develop a shared understanding of bullying and co-design the research questions and methods for data collection and analysis in phase two.

In the first session, we explained the purpose and aims of the research and explored the differences between qualitative and quantitative research. Given that a fundamental aspect of participatory research is shared meaning and co-construction of knowledge (Wilkinson \& Wilkinson, 2018) we established a shared understanding and definition of bullying from the perspective of the research team. This was particularly important for the initial stages of the study, as research suggests that young people and adults understand bullying differently (O'Brien, 2009; Eriksen, 2018). Acknowledging this criticism in current understandings of bullying and creating the opportunity for both the young people and staff at RBAir to express their own understandings was an important mechanism for trust and relationship building during the participatory research process. We discussed several definitions from literature and policy documents and the generally agreed criteria of repetition, intentionality and an imbalance of power. Box one shows the bullying definition we developed for the project.

\section{INSERT BOX ONE HERE}

This definition corroborates the wider literature in terms of the three criteria, though explores these in more detail. For example, the young co-researchers talked about one-off physical attacks and cyber-bullying that is not necessarily repeated but has lasting effects. In terms of intentionality, they acknowledged that how the bullied person perceives bullying is important, but that this needs to be taken alongside perceptions of everyone involved, including the bully and bystanders. Finally, the wider social context underpinning bullying was stressed as crucial in understanding bullying; a concept that is emerging in the research literature and going beyond the individual personality traits of bully and bullied (Schott \& Søndergaard, 2014). 
This definition was subsequently used to inform the development of research questions and data collection in phase two. Indeed the ethos of 'shared understanding' in terms of our shared knowledge was taken forward to the second phase when we actively sought the views of other young people with further unique experiences of bullying and self-exclusion.

In the second session, we reflected on our bullying definition and ensured all research team members were satisfied. We then moved on to share vignettes of different bullying situations, which were developed based on the discussions in session one as well as the findings from the initial study at Red Balloon (O'Brien, 2017). Box two provides an example of one of the vignettes and the questions which followed.

\section{INSERT BOX TWO HERE.}

The young people considered these vignettes relation to their own experiences in the lead up to their self-exclusion, and the discussion that followed covered what research questions would be interesting to explore at the four other Red Balloon Centres. This method was particularly effective in discussing these sensitive issues where direct questioning was not appropriate. The young people could choose to remove themselves from their own situation, and comment on the hypothetical situation presented to them if they felt this was fitting.

We then discussed data collection methods for phase two, and focus groups were identified as the most appropriate method. It has been suggested that creative methods are more facilitative of young people's engagement (Cremin, Mason \& Busher, 2011) and based on previous experience we thought the young people might opt for creative methods. However, the young co-researchers suggested that due to commonalities in their experiences, most young people attending Red Balloon are likely to be comfortable sharing their experiences with each other and focus groups would encourage a rich dialogue. Although this method is often viewed as conventional, it is also used in participatory research, and Gallagher (2008) postulates that the social interactions involved in co-producing knowledge is what makes the research 
participatory; not the methods themselves. We then began drafting the focus group topic guide and follow on questions which the young co-researchers recommended should be sent to the Centres ahead of time to prevent young people feeling anxious about the unknown. Pickles (2019) also recommends this as good practice so young people can prepare if they do not want to answer specific questions.

Our third session took place online through email exchanges due to illness and the RBAir Centre relocating premises. The intention was to further develop the topic guide and research questions but due to our research team being small in size, we were able to cover most of this in the second session. However, in order to strengthen the trustworthiness of our research, the final topic guide and questions were sent to the co-researchers at RBAir as a way of member checking, and everyone agreed that they represented what we had discussed. The focus group topics concentrated on: the decision to leave school, reactions from the wider peer group, support structures in school, potential early interventions, and policies, process and legislation surrounding bullying and self-exclusion.

\section{Phase two: data collection}

Ideally, the research team would have collaboratively collected the data. Young co-researchers would have been trained and supported to do so by the adult researchers (Bradbury-Jones, Isham \& Taylor, 2018). However despite our efforts, funding and time constraints prevented this from happening. Consequently, data collection was undertaken by us (the university researchers) and we conducted a focus group at each of the four Red Balloon Centres. A purposive sampling approach was used with two specific criteria; firstly we wanted to speak to those who had experienced bullying as a contributing factor to their self-exclusion, and secondly we were mindful that participation in the study could potentially distress those who were not ready to share their experiences, so it was imperative that only those young people unlikely to feel distressed by participating in the study were involved. 
We did not aim for representativeness of the wider Red Balloon population, so any young people meeting the criteria were invited to take-part. Red Balloon staff members at each Centre became the research gatekeepers. They knew the young people well, and were therefore able to approach those they believed were unlikely to feel distressed through participation. They were also very supportive of the research and facilitating recruitment, something identified as important by others conducting participatory research with young people on sensitive issues (see Whittington, 2019).

Recruitment of young people through gatekeepers can perpetuate the marginalisation of unheard voices; for example Horgan (2017) found that schools were likely to select articulate students and those who would represent their schools well. However, given the nature of our research and the different stages young people at Red Balloon were at, collaboration with staff was essential to ensure the recruitment was undertaken ethically to avoid undue distress. Furthermore given that we had worked with Red Balloon previously, we were mindful of the close working relationship the staff have with the young people. Working closely with them through the recruitment process strengthened the study and facilitated a power shift.

Thirteen young people were willing and participated across the four Centres. Each focus group consisted of between three and four young people; ten females and three males aged approximately 13 to 16 years across a variety of socio-economic and ethnic backgrounds. Although considered a small sample size focusing on the lived experience of a few, there was diversity in experiences among the young people, as each of their stories were unique to their individual experiences.

Young people were asked if they would like a Red Balloon staff member to sit in on the discussion and in all focus groups they chose not to. Focus groups began with an icebreaker to help the young people feel comfortable with the researchers. In line with our ethos of 'shared understanding, in focus group one, the young people developed collective ground rules 
including listening to each other and respecting different points of view. These were taken to the next focus groups and developed further by the young people as they felt necessary. This process gave ownership to the young people in deciding how they wanted to conduct the focus group discussion as well as reminding them of their right to not answer every question if they did not want to. With the young people's consent, the discussions were audio recorded and later transcribed. At the end of each focus group, the young people were thanked for their time and contributions and reminded that they could talk to the Red Balloon staff or contact the researchers if they had any questions or concerns.

\section{Data analysis and findings}

Following data collection, our intention from the outset had been to collaboratively analyse the data with the young people and staff members from RBAir. The importance of young people's involvement in data analysis is recognised through participatory research methodology, setting it aside from traditional research designs (MacKenzie, Hoverman \& Baldwin, 2012). However, by this time the young people had to prioritise preparation for upcoming exams, and analysis could not be delayed due to funding constraints. Instead, we used the focus group topics identified in phase one as a starting point as they were rooted in the young people's perspectives, and developed these through thematic analysis (Braun \& Clarke, 2006). This practice contributed to our understanding about the need for flexibility within the participatory research process (Brady et al., 2018) and that young people can only be expected to actively contribute when the research takes place outside of other demands on their time, as well as when funding allows.

The findings (O'Brien \& Dadswell, 2019), showed that for these young people, bullying leading to self-exclusion from school was underpinned by anxiety. The young people's experiences were shaped by the dynamics of their friendships, including 'fake friends' and apathetic or conflicted friends; issues around seeking support, for example not wanting support, 
only receiving support at 'crisis point', and support inadequate for their needs; and institutional factors in mainstream schools, such as too much or too little security, and ineffective implementation of anti-bullying policies. These factors led to the gradual withdrawal from school, and eventual self-exclusion.

\section{Ethical considerations}

Ethical approval was granted by the School of Education and Social Care Research Ethics Panel at Anglia Ruskin University. However, the ethics associated with participatory research were taken into consideration in designing the study and negotiated throughout. As discussed, the topic of bullying is sensitive and all of the young people involved in this research had experienced trauma as a result of bullying leading to their self-exclusion. Therefore, we were mindful of how we approached the research and discussed these issues with the young people. Both researchers have experience working with young people on sensitive issues, and worked closely with Red Balloon staff members to ensure the research was conducted in a way that respected the particular needs of the young people. In addition, the focus group topic guide and questions were developed alongside young people with lived experience of bullying and selfexclusion, ensuring appropriateness to the study.

Prior to phase one commencing at RBAir, we provided reader-friendly participant information sheets (PIS) for young people to decide themselves whether or not they wanted to participate as co-researchers. Prior to data collection in phase two, all Centres were provided with PISs to distribute to those young people who had experienced bullying and were unlikely to experience distress due to involvement. Each young person consented for themselves rather than seeking consent from parents/carers, though the latter were informed of the study and could contact the university researchers if they had any queries. Coyne (2010) argues that parent/carer consent is not always necessary in social research and writes about the difference in the terms 'consent' and 'assent', which are normally used to distinguish: "[the] legal competency of children over 
and under 16 years in relation to research" (p.228). She further adds that children in England do not give assent but rather have the legal right to consent once deemed Gillick competent. Balen, Blyth, Calabretto, Fraser, et al. (2006) discuss the principles of 'Gillick competency' in their paper on involving children in health and social research. Following the ruling in the House of Lords in Gillick v. West Norfolk Area Health Authority (1985), a young person under the age of 16 can consent to medical treatment without parental knowledge or consent. These principles, known as 'Gillick competency' have subsequently been applied to medical and social research. They stipulate that those under the age of 18 are able to consent to their own participation, providing they have sufficient understanding and knowledge about the subject area and what will be required. Assessing competence to consent must be done on an individual basis so when a young person is deemed competent, parental consent is not required (Balen et al., 2006). All participants in this research were aged 13 years and over and were deemed competent to consent. Whittington (2019) reflects that using the principles of Gillick insured that young people were supported in their decision on whether or not to consent to her research. By working flexibly with Red Balloon staff, we were also able to ensure young people were supported in the consent process. For example, when we arrived at one Centre, we were informed that the young people wanted to meet us first before they decided to participate in the focus group. Though somewhat unsettling for us as researchers, it was fair that the young people wanted to feel comfortable with us before agreeing to share their sensitive stories. Certainly, this process of young people giving consent for themselves can contribute to wider learning in relation to how they make decisions about other issues in their lives (Whittington, 2019). Using Gillick competency also enabled the young people to make their own decisions about the research away from parental influence (Pickles, 2019), which might have hindered participation. 


\section{Reflections on participation}

Given the adult initiated proposal and data analysis conducted by adults, we reflected on whether this research could be labelled 'participatory'. Holland, Renold, Ross and Hillman (2010) note that some research has been called participatory simply because young people took part as participants, despite the methods and other elements being decided by adults. They highlight the importance of how participation is conducted, rather than how much participation is achieved, to indicate meaningful participation. Participation was central to this research and we ensured that young people had opportunities to be involved in the research process through both phases. However, this had to be flexible using both face-to-face and online methods and with the collaboration and support of the Red Balloon staff. The process of conducting this participatory research has highlighted how the intentions and realities of participatory approaches are often in conflict with one another. Our reflections of this process are discussed below under the themes of power dynamics, practicalities of participation and partnership working.

\section{Power dynamics}

Phase one was underpinned by the value placed on the individual contributions of each team member; young people brought their own lived experiences of bullying and self-exclusion, RBAir staff brought extensive knowledge from their role in supporting and teaching these young people, and the university researchers brought academic knowledge on bullying and self-exclusion, as well as experience of conducting research with young people. All of these contributions enabled us to develop our shared understanding of bullying as well as the focus group questions and analytical framework. In turn, this influenced the power dynamics in phase two.

Horgan (2017) argues that all research with children is unequal due to adult initiated and decided agendas. Although she states these inequalities cannot be eradicated, she also suggests 
it is important to acknowledge them and that researchers should question typical consent procedures and build children's capacity. Through our process of seeking informed consent directly from the young people, the onus was entirely on them to decide for themselves whether or not they wanted to participate, rather than seeking additional consent from an adult which retracts power from the young person. Bovernick et al. (2018) note that participatory research designs are powerful in addressing power discrepancies. They refer to the data collection process and suggest that young respondents have been shown to engage with data collection in sensitive areas when they are aware that others in a similar situation have been involved in designing the research. In phase two of the current study, some young people commented that they were impressed to see that the bullying definition, methods and overall research approach had been co-designed with other Red Balloon students. This aspect had encouraged them to take part and enabled them to relax into the dialogue as the focus groups developed. It also made clear our commitment to representing their experiences and perspectives, rather than our own, which contributed to a shift in power from us as adults, to the young people. Indeed, Horgan (2017) also suggests researchers should adopt the 'least adult role', a concept coined by Mandell (1991), which stipulates that researchers should try to 'blend in' with a child's world to build relationships with children in order to understand their world from their perspective. We argue the 'least adult role' is not always necessary in participatory research, rather the development of a partnership between adults and young people is required. Power can shift between the adult researchers and the young researchers throughout the participatory research process, as identified by Jones (2004) and O'Brien, Moules and Munn-Giddings (2018). This shifting of power can occur between the stages of the project and even in individual meetings or activities as the individual contribution of each team member is realised. O'Brien, Moules and Munn-Giddings (2018) report on how the Dual-Axis Model of Participation; a model focusing on the power shift between young people and adults in 
research projects, with a particular focus on 'decision-making' and 'initiation' (Moules \& O'Brien, 2012), was extended to include the individual and group contributions around 'ideas' and 'knowledge' to become the Axis Model of Participation. These additional concepts recognise that not all 'ideas' lead to decisions but that all ideas are valid and contribute to the overall decision-making process; 'knowledge' recognises the unique contribution of all team members. For example, in this study, 'ideas' were generated around data collection methods. Both creative and traditional methods were considered, and the young co-researchers opted for the traditional focus group method with valid justifications which led to an agreement between the research team that this was the best option. 'Knowledge' was evident in the lived experiences of the young people, the support knowledge of Red Balloon staff and the theoretical and policy knowledge of the researchers. The underlying principle of the Axis Model of Participation is that power in relation to these four concepts shifts all the time - sometimes the power is with the young people, sometimes it is with the adults and sometimes the power is shared equally between adults and young people. In our study, power constructs changed all the time. In phase one, academic and lived knowledge about bullying and self-exclusion were brought together to develop our understanding of what bullying is, as well as developing the focus group questions. During each of the three sessions the 'power' in the team shifted as young people relied on us for our expertise in conducting research whilst we relied on them for expertise on their lived experiences as well as responding to our queries and questions. In phase two, we were not only reliant on Red Balloon staff to facilitate access to and support for the young people but we were also dependent on the young people in each focus group to provide answers to our questions. In both phases however, a relaxed discourse developed and at times the 'power' was shared between all. 


\section{Practicalities of participation}

To facilitate participation in both phases, we ensured specific accessible information was sent to the gatekeepers ahead of time. Our knowledge of conducting previous participatory research projects with young people, where they had contributed to developing PISs for the studies, ensured that the PISs for this study were reader friendly and accessible. Only relevant study details and the requirements of young people were provided.

Prior to phase one we met with a staff member from RBAir to discuss meaningful ways we could involve young people as co-researchers. Certainly Cargo, Delormier, Lévesque et al. (2008) suggest this is good practice, and that within community based participatory research projects, agreements between parties need to be considered ahead of time around roles and responsibilities and revisited regularly. In these initial meetings, we spoke about the requirements not only of the young people but also of RBAir in facilitating their ethical and meaningful involvement. Consequently, discourse around levels of participation continued throughout the project.

Our close working relationship with Red Balloon staff enabled us to develop effective working relationships with the young people in both phases, which enhanced the participation experience for all. Kim (2016) notes that if young people do not trust the adults associated with the project then they are unlikely to participate. We already had a good working relationship with some Red Balloon senior staff including staff at RBAir due to prior research (O'Brien, 2017), but needed to extend that to staff at all Red Balloon Centres to support us in gaining the trust of young people. In the development stages of the study, we made contact with each Centre to introduce ourselves and enquire about the possibility of conducting research with them. Sending the PISs ahead of time in phase two meant that the staff and young people were informed about the research and were prepared for our visit. We were however also aware of the demands young people have on their time and the impact this could have on their ability 
and indeed desire to participate. For example, a couple of young people joined some focus groups late or left early due to other classes or engagements that they had; but this did not take away from their contribution whilst they were present. Further, in phase one, it was up to us (university researchers) to enable the young co-researchers to participate as much as they wanted to. We did this by arranging to meet at RBAir on the same day over a number of alternate weeks to tie in with their school timetable. When face-to-face meetings became problematic, we diverted to online participation via email. We also had to accept that although the young people contributed to the dialogue in developing the bullying definition and the focus group questions, they might not have wanted to contribute to these activities online. Consequently, we provided a two-week window for responses to emails and explained that if we did not receive responses, we would take this as their acceptance.

Time was a limitation within this study, which had an impact on participation as identified by Kim (2016). We initially met the young co-researchers for phase one in April 2019 and began data collection for phase two in June 2019. During this time we experienced disruptions in terms of Easter holidays as well as times when our sessions were moved or indeed cancelled altogether. Our initial intention was to have five sessions with the young co-researchers. Not only did this give us limited time to develop the methods, it also gave limited time to collect and interpret the data and receive consensus from the research team before the end of the school year. This was exacerbated by exams, which had to be a priority. In phase two we had to respect the wishes of those who did not want to participate in the focus groups. No reasons were provided as to why they did not want to participate, but perhaps the use of an additional anonymous method such as an online questionnaire might have facilitated their participation. In phase one, the co-researchers spoke about an additional method, to not only capture the views of those unwilling/unable to participate in the focus groups, but also to include those receiving support online through RBAir. We agreed to adapt the focus group questions into an 
online questionnaire for this purpose, which would be emailed by RBAir. However due to the constraints already mentioned, sending out the online questionnaire became problematic.

Nevertheless, through the focus groups our role took on that of facilitators as the young people shared their stories and discussed together the issues underpinning bullying and self-exclusion from school. Issues relating to friendships, timely support to prevent school exclusions as well as the importance of feeling listened to, underpinned these discussions. Bagnoli and Clark (2010) suggest that it is these interactions between the participants themselves that generate the focus group data rather than the interactions between the participants and the researcher.

\section{Partnership working}

Building a strong working relationship with Red Balloon and working in partnership with their staff members and young people was essential for gaining access to this marginalised group, ensuring our research was conducted ethically and sensitively, and encouraging and supporting the young people throughout their participation. However, the time and energy required to forge meaningful relationships for participatory research is rarely considered in the literature (Foster, 2016).

The young people in the research are no longer attending mainstream school and go unrecognised in official statistics. As such, they can be considered a marginalised group whose perspectives are missing from the literature. Bovarnick, Peace, Warrington and Pearce (2018) found that some marginalised groups operate a transient lifestyle, which can be a barrier to engagement in participatory research. Being out of mainstream education could be considered a transient experience, though a more prominent barrier for our participants was the anxiety they continue to experience related to trauma in the form of bullying. To facilitate engagement, Bovarnick, Peace, Warrington and Pearce (2018) suggest collaborating with specialist services who work with marginalised groups, whilst also acknowledging that the demanding priorities within those services will often take precedence over the research. 
Banks, Armstrong, Carter, Graham, et al. (2013) have written on everyday ethics in community-based participatory research and highlight the importance of how partnerships are established, and particularly how power is distributed within the partnership. They note that partnerships evolve slowly over time as trust is built, which was the case in the current study. As mentioned, the first author had previously worked with Red Balloon and built a trusting relationship with RBAir, which facilitated the smooth running of phase one. This is in line with Tremblay, Kingsley, Gokiert, and Benthem (2018) who state that building relationships with frontline staff who have direct contact with the intended participant group is critical. With the support of Red Balloon, we were enabled to access the young people for this study and hear their experiences directly. Such a partnership also enabled the development of the research team as the young co-researchers witnessed the interactions between Red Balloon staff and university researchers. Consequently, this put them at ease and encouraged them to engage as the Red Balloon staff modelled their contributions to the discursive sessions. The contributions of the Red Balloon staff also provided invaluable insight based on their experiences of supporting young people after self-exclusion, and this further enhanced the research findings. For those participating in phase two, knowing that the research had been developed with RBAir helped to initiate our relationship with both staff members and young people in the other Centres and demonstrated our commitment to representing their experiences and perspectives.

\section{Conclusion}

This paper has discussed a participatory research project involving a research team of adults and young co-researchers that explored bullying and self-exclusion from school alongside those with lived experiences of this issue. Our research team worked together through dialogue and written and online formats to co-design the research method, and agree upon an analytical framework, therefore ensuring the developed study was rooted in lived experiences of the issue. 
This research adds to the literature on the need for flexibility and appropriate responses to experiences, when involving young people in sensitive research (Brady et al., 2018). We needed to provide enough flexibility across the two phases, to ensure the research was conducted ethically and sensitively, whilst encouraging and supporting the young people throughout their participation. Although we were met with limitations during this process, building relationships with the young people was paramount to the project success. This was possible through Red Balloon staff members becoming 'brokers' for the research, vouching for the credibility of the researchers and influencing the recruitment of the young people (Clarke, 2011), as well as supporting them throughout and afterwards.

This paper offers a strong rationale for involving young people in further research to develop support that better fits the needs of bullied young people and reduce the incidences of selfexclusion. Furthermore, putting the lived experiences of young people at the centre of the research not only enhances the findings, but can also realise benefits for the young people themselves, both individually and collectively. For example, Bovarnick et al. (2018) found that involvement in participatory research provided opportunities for children and young people to acquire new skills, develop their confidence and strengthen their resilience. 'Selfrepresentation' may also have therapeutic benefits for some individuals, while representing these experiences and perspectives more widely can raise awareness that benefits the community of children and young people affected by the issue and positions them as political agents for social change.

Although this study does not claim generalisability, it is possible that the process of active and flexible involvement could be replicated elsewhere. Involving young people in research recognises their unique experience and knowledge that goes beyond the current literature on this topic. The intention from this work is that going forward adults will be enabled to better 
understand the experiences of self-excluded young people and make positive changes to their social and learning environments. 


\section{References}

Bagnoli, A., \& Clark, A. (2010). Focus groups with young people: a participatory approach to research planning. Journal of youth studies, 13(1), 101-119.

Balen, R., Blyth, E., Calabretto, H., Fraser, C., Horrocks, C., \& Manby, M. (2006). Involving Children in Health and Social Research: 'Human becomings' or 'active beings'?. Childhood, 13(1), 29-48.

Banks, S., Armstrong, A., Carter, K., Graham, H., Hayward, P., Henry, A., Holland, T., Holmes, C., Lee, A., McNulty, A. and Moore, N. (2013). Everyday ethics in community-based participatory research. Contemporary Social Science, 8(3), pp.263-277.

Benbenishty, R., Astor, R. A., Roziner, I., \& Wrabel, S. L. (2016). Testing the causal links between school climate, school violence, and school academic performance: A cross-lagged panel autoregressive model. Educational Researcher, 45(3), 197-206.

Billington, K.F. (2018). Using an active listening approach to consider the views of three young people on the topic of missing education. Educational Psychology in Practice, 34(4), 337-351.

Bird, D., Culley, L., \& Lakhanpaul, M. (2013). Why collaborate with children in health research: an analysis of the risks and benefits of collaboration with children. Archives of Disease in Childhood-Education and Practice, 98(2), 42-48.

Bovarnick, S., Peace, D., Warrington, C., \& Pearce, J. J. (2018). Being heard: promoting children and young people's involvement in participatory research on sexual violence: findings from an international scoping review. The International Centre: Researching child sexual exploitation, violence and trafficking, University of Bedfordshire. Retrieved March 52020 from

https://uobrep.openrepository.com/uobrep/bitstream/10547/623282/3/UoB_BeingHeardreport $\% 281 \% 29 . p d f$

Bradbury-Jones, C., Isham, L., and Taylor, J. (2018). The complexities and contradictions in participatory research with vulnerable children and young people: a qualitative systematic review. Soc. Sci. Med. 215, 80-91. doi: 10.1016/j.socscimed.2018.08.038.

Brady, L. M., Templeton, L., Toner, P., Watson, J., Evans, D., Percy-Smith, B., \& Copello, A. (2018). Involving young people in drug and alcohol research. Drugs and Alcohol Today. 18(1), 28-38. DOI 10.1108/DAT-08-2017-0039

Braun, V., and Clarke, V. (2006). Using thematic analysis in Psychology. Qualitative Research in Psychology, 3, 77-101.

Brown, V., Clery, E., \& Ferguson, C. (2011). Estimating the prevalence of young people absent from school due to bullying. National Centre for Social Research. Retrieved July 102019 from: https://www.anti-bullyingalliance.org.uk/sites/default/files/field/attachment/estimatingprevalence-young-people.pdf 
Cargo, M., Delormier, T., Lévesque, L., Horn-Miller, K., McComber, A., \& Macaulay, A. C. (2008). Can the democratic ideal of participatory research be achieved? An inside look at an academic-indigenous community partnership. Health Education Research, 23(5), 904-914.

Centre for Social Justice. (2016). Bullying and Self-Exclusion: Who Cares? Roundtable Report 19 $9^{\text {th }}$ July 2016. Retrieved September 202019 from:

https://www.centreforsocialjustice.org.uk/core/wp-content/uploads/2016/11/Bullying-RT-

Report-1.pdf

Clark, T. (2011) 'Gaining and maintaining access: Exploring the mechanisms that support and challenge the relationship between gatekeepers and researchers'. Qualitative Social Work, 10 (4), 485-502.

Coyne, I. (2010). Research with children and young people: The issue of parental (proxy) consent. Children \& Society, 24(3), 227-237.

Cremin, H., Mason, C., \& Busher, H. (2011). Problematising pupil voice using visual methods: Findings from a study of engaged and disaffected pupils in an urban secondary school. British Educational Research Journal, 37(4), 585-603.

Deuchar, R., \& Bhopal, K. (2013). 'We're still human beings, we're not aliens': promoting the citizenship rights and cultural diversity of Traveller children in schools: Scottish and English perspectives. British educational research journal, 39(4), 733-750.

Eriksen, I. M. (2018). The power of the word: students' and school staff's use of the established bullying definition. Educ. Res. 60, 157-170. doi: 10.1080/00131881.2018.1454263

Fitzgerald, R., Graham, A., Smith, A., \& Taylor, N. (2009). Children's participation as a struggle over recognition: Exploring the promise of dialogue. In: B. Percy-Smith, and N. Thomas, (eds). A handbook of children and young people's participation: Perspectives from theory and practice. pp.293-305. London: Routledge Taylor and Francis Group.

Foster, V. (2016). Collaborative Arts-Based Research for Social Justice. London: Routledge.

Fox, R. (2013). Resisting participation: Critiquing participatory research methodologies with young people. Journal of Youth Studies, 16 (8), 986-999.

Freeman, C., Nairn, K., \& Sligo, J. (2003). 'Professionalising' participation: From rhetoric to practice. Children's Geographies, 1(1), 53-70.

Gallagher, M. (2008). Power is not an evil: Rethinking power in participatory methods. Children's Geographies, 6(2), 137-150.

Holland, S., Renold, E., Ross, N. J., \& Hillman, A. (2010). Power, agency and participatory agendas: A critical exploration of young people's engagement in participative qualitative research. Childhood, 17(3), 360-375.

Horgan, D. (2017). Child participatory research methods: Attempts to go 'deeper'. Childhood, 24(2), 245-259.

James, A. (2007). Giving Voice to Children's Voices: Practices and Problems, Pitfalls and Potentials. American Anthropologist, 109(2), 261-272. 
Jones, A. (2004). Involving Children and Yong People as Researchers. In: S. Fraser, V. Lewis, S. Ding, M. Kellett, \& C. Robinson, (eds). Doing Research with Children and Young People, pp.113-130. London: Sage Publications.

Kellett, M. (2010a). Small shoes, Big Steps! Empowering Children as Active Researchers. American Journal of Community Psychology, 46,195-203.

Kellett, M. (2010b). Rethinking Children and Research: Attitudes in Contemporary Society. New Childhoods series. London: Continuum International Publishing Group.

Kim, J. (2016). Youth Involvement in Participatory Action Research (PAR). Critical Social Work, 17(1), 38-53.

Komulainen, S. (2007). The Ambiguity of the Child's 'Voice' in Social Research. Childhood, 14(11), 11-28.

MacKenzie, J., Tan, P.L., Hoverman, S. \& Baldwin, C. (2012). The Value and limitations of Participatory Action Research methodology. Journal of Hydrology, 474, 11-21.

Mandell, N. (1991). The least-adult role in studying children. In: Waksler, FC. (ed.) Studying the Social Worlds of Children: Sociological Reading, pp. 38-59, London: Falmer Press.

McNamee, S. \& Seymour, J. (2012). Towards a sociology of 10-12 year olds? Emerging methodological issues in the 'new' social studies of childhood. Childhood, 20(2), 156-168.

Moules, T. \& O'Brien, N. (2012). Participation in perspective: reflections from research projects. Nurse Researcher, 19(2), pp.17-22.

Moules, T, \& O'Brien, N. (2016). The child's perspective and service delivery. In D. DeBell (ed). Public Health for Children (2nd edition), pp. 247-270. London: Taylor and Fisher (Routledge).

O'Brien, N. (2009). Secondary school teachers' and pupils' definitions of bullying in the UK: a systematic review. Evidence \& Policy: A Journal of Research, Debate and Practice, 5(4), 399427.

O'Brien, N. (2017). An exploratory study of bullied young people's self-exclusion from school. Evidence: presented at meetings of the All Party Parliamentary Group on Bullying 2011-2016. Retrieved November 172019 from:

https://www.researchgate.net/publication/318361810_APPG_on_Bullying_Report_2011-16 pp 25-26.

O'Brien, N., Moules, T., \& Munn-Giddings, C. (2018). Negotiating the research space between young people and adults in a PAR study exploring school bullying. In M. Torronen., C. MunnGiddings, C., \& L.Tarkiainen (eds), Reciprocal Relationships and Well-Being: Implications for Social Work and Social Policy, pp. 160-175, Oxon: Routledge.

O'Brien, N. (2019). Understanding alternative bullying perspectives through research engagement with young people. Frontiers in Psychology, 10, 1984. https://doi.org/10.3389/fpsyg.2019.01984 
O'Brien, N., \& Dadswell, A. (2019). Working with young people to explore bullying and selfexclusion from school. Final Report. Anglia Ruskin University Chelmsford. Retrieved December 202019 from: http://arro.anglia.ac.uk/id/eprint/704884

O'Brien, N., \& Moules, T. (2007). So round the spiral again: a reflective participatory research project with children and young people. Educational Action Research Journal, 15(3), 385-402.

Olweus, D. (1995). Bullying or peer abuse at school: Facts and intervention. Current directions in psychological science, 4(6), 196-200. doi: 10.1111/1467-8721.ep10772640

Percy-Smith, B. (2015). Negotiating active citizenship: Young people's participation in everyday spaces. In: Politics, Citizenship and Rights. Geographies of Children and Young People (7). London: Springer. ISBN 9789814585569. Retrieved March 12020 from http://eprints.hud.ac.uk/id/eprint/23226/1/Geogs_o

Percy-Smith, B., \& Malone, K. (2001). Making children's participation in neighbourhood settings relevant to the everyday lives of young people. PLA notes. 42, 18-22.

Pickles, J. (2019). Including and involving young people (under 18's) in hate research without the consent of parents. Qualitative Research, 20(1) 22-38. DOI: 10.1177/1468794118816622

Red Balloon Learner Centres. (May 2015). Information for parents and carers on bullying: Red Balloon Learner Centres in association with the Anti-Bullying Alliance. Retrieved September $\quad 30 \quad 2019$ from: http://fluencycontent2-schoolwebsite.netdnassl.com/FileCluster/TheRedBalloon/MainFolder/5_News_and_Events/02_Latest_News/ABA -BULLYING-PACK.pdf

Red Balloon. (2019). Retrieved September 302019 from: http://www.redballoonlearner.org

Rigby, K. (2019). How Australian parents of bullied and non-bullied children see their school responding to bullying, Educational Review, 71(3), 318-333, DOI:10.1080/00131911.2017.1410104

Salmivalli, C. (2010). Bullying and the peer group: A review. Aggression and Violent Behavior, 15(2), 112-120.

Schott, R. M., \& Søndergaard, D. M. (Eds.). (2014). School bullying: New theories in context. Cambridge: Cambridge University Press.

Smith, P. K. (2014). Understanding school bullying: Its nature and prevention strategies. London: Sage.

Stoudt, B.G. (2009). The Role of Language \& Discourse in the Investigation of Privilege: Using Participatory Action Research to Discuss Theory. Develop Methodology, \& Interrupt Power. Urban Review, 41, 7-28.

Thambirajah, M.S., Grandison, K.J. \& De-Hayes, L. (2008). Understanding school refusal: A handbook for professionals in education, health and social care. London: Jessica Kingsley.

Thomson, P., and Gunter, H. (2008). Researching Bullying with students: a lens on everyday life in an 'innovative school'. Int. J. Inclusive Educ. 12, 185-200. doi: $10.1080 / 13603110600855713$ 
Tremblay, M., Kingsley, B., Gokiert, R., \& Benthem, G. (2018). Engaging Vulnerable Youth in Community-Based Participatory Research: Opportunities and Challenges. Journal of Community Engagement \& Higher Education, 10(3), 52-60.

United Nations Convention on the Rights of the Child (1989). Retrieved January 302020 from: https://downloads.unicef.org.uk/wp-content/uploads/2016/08/unicef-convention-rights-childuncrc.pdf?.ga=2.62798373.86784612.1583922018-1877893560.1583922018

Vaillancourt, T., McDougall, P., Hymel, S., Krygsman, A., Miller, J., Stiver, K., \& Davis, C. (2008). Bullying: Are researchers and children/youth talking about the same thing?. International Journal of Behavioral Development, 32(6), 486-495. Doi $10.1177 / 0165025408095553$

Whittington, E. (2019). Co-producing and navigating consent in participatory research with young people. Journal of Children's Services, 14(3), 205-216. DOI 10.1108/JCS-02-20190007

Wilkinson, C., \& Wilkinson, S. (2018). Principles of Participatory Research. In I Coyne \& B Carter (eds) Being Participatory: Researching with Children and Young People, pp. 15-35, Cham: Springer. 